\title{
Memorias de la izquierda trotskista argentina sobre la última dictadura. Representaciones en la prensa partidaria en torno a las efemérides del 24 de marzo (2014-2018)
}

\author{
Nicolás Cosic* \\ Universidad Nacional de General Sarmiento, Argentina \\ n.cosic03@gmail.com
}

\section{RESUMEN:}

En este artículo presentamos un análisis exploratorio de las memorias de la izquierda trotskista argentina sobre la última dictadura militar (1976-1983). Tomando el período 2014-2018, esbozamos una caracterización exhaustiva de la estructura y dinámica de las mismas, haciendo especial hincapié en las relaciones antagónicas que presentan frente a las memorias oficiales del kirchnerismo y el macrismo. Proponemos, por último, una serie de elementos claramente distintivos que nos permiten englobarlas bajo una misma categoría.

Palabras ClaVe: Memorias, Izquierda trotskista argentina, Derechos Humanos, 24 de marzo, Kirchnerismo, Macrismo.

\section{INTRODUCCIÓN}

El 24 de marzo de 1976 se instauraba en la Argentina la dictadura cívico-militar más represiva y sangrienta de su historia. La misma, con el objetivo declarado de acabar con la "subversión”, dejaría tras de sí un saldo de 30.000 desaparecidos, 500 niños apropiados y la implantación decisiva del modelo económico neoliberal-de consecuencias socio-económicas catastróficas y absolutamente condicionantes para el futuro desarrollo de la sociedad argentina tras la recuperación de la democracia (1983).

Este acontecimiento medular de la historia reciente argentina y sudamericana generó, desde los tempranos años ochenta hasta la actualidad, diversas y cambiantes formas de rememoración que entraron en conflicto en la esfera pública (Lvovich y Bisquert, 2008). Aunque se han estudiado con bastante profundidad las memorias de diferentes actores socio-políticos, las memorias de los partidos políticos en general y de la izquierda partidaria en particular constituyen todavía terrenos poco explorados.

Partiendo desde aquí, en este trabajo nos propusimos estudiar en particular las memorias de la izquierda trotskista argentina sobre la última dictadura, fundamentalmente sobre el significado atribuido al golpe de estado del 24 de marzo. Analizamos, más puntualmente, sus representaciones en las respectivas prensas partidarias durante los últimos cinco años, caracterizados por la finalización de la etapa kirchnerista y el ejercicio del poder de la nueva administración macrista: dos gestiones con miradas diversas (y, en muchos aspectos, opuestas) en torno a la memoria de los años 1970.

Hemos decidido enfocarnos, de forma preliminar, sólo en la prensa on line de los partidos trotskistas más representativos, provenientes casi en su totalidad de la "diáspora” de la tradición morenista: el Movimiento Socialista de los Trabajadores (MST), el Nuevo MAS (NMAS), la Izquierda Socialista (IS), el Partido de 
los Trabajadores Socialistas (PTS) y el Partido Obrero (PO). Nos concentramos, por tanto, en once fuentes de las respectivas prensas partidarias, lo que nos permitió comparar y detectar las continuidades y rupturas discursivas tras el cambio de gobierno. Se trató, en todos los casos, de artículos relacionados a las efemérides del 24 de marzo.

Nuestro objetivo general consistió en analizar, caracterizar e intentar explicar la estructura y dinámica de estas memorias particulares. Es decir, por un lado, dar cuenta de la articulación de los elementos discursivos más persistentes en las memorias trotskistas, y, por el otro, evidenciar aquellas transformaciones operadas en el seno o en los márgenes de dicha articulación. Es por ello que podemos inscribir este trabajo en el marco general de los estudios de memoria, en tanto y en cuanto pretendimos desde un principio comprender este fenómeno como un proceso socio-cultural y político, que está implicado íntimamente en la constitución de identidades colectivas (Lvovich y Bisquert, 2008) -en este caso, de identidades partidarias- a través de la construcción de relatos o narrativas que intentan darle sentido a un pasado determinado. Estas narrativas, consustanciales del fenómeno a analizar, no pueden ser entendidas como elementos estáticos, reificados, sino que, por el contrario, deben conceptualizarse como entretejidos

Nuestro objetivo general consistió en analizar, caracterizar e intentar explicar la estructura y dinámica de estas memorias particulares. Es decir, por un lado, dar cuenta de la articulación de los elementos discursivos más persistentes en las memorias trotskistas, y, por el otro, evidenciar aquellas transformaciones operadas en el seno o en los márgenes de dicha articulación. Es por ello que podemos inscribir este trabajo en el marco general de los estudios de memoria, en tanto y en cuanto pretendimos desde un principio comprender este fenómeno como un proceso socio-cultural y político, que está implicado íntimamente en la constitución de identidades colectivas (Lvovich y Bisquert, 2008) -en este caso, de identidades partidarias- a través de la construcción de relatos o narrativas que intentan darle sentido a un pasado determinado. Estas narrativas, consustanciales del fenómeno a analizar, no pueden ser entendidas como elementos estáticos, reificados, sino que, por el contrario, deben conceptualizarse como entretejidos

de tradiciones y memorias individuales, en diálogo con otros, en estado de flujo constante, con alguna organización social algunas voces son más potentes que otras porque cuentan con mayor acceso a recursos y escenarios- $y$ con alguna estructura, dada por códigos culturales (Jelin, 2001, p. 22).

En este sentido, uno de los aspectos que más nos interesaron, por tratarse de memorias partidarias, fue el plano de la "lucha por las representaciones del pasado" absolutamente ligadas a las "luchas por el poder" (Jelin, 2001, p. 36).

La pregunta general que guio esta investigación fue la siguiente: ¿es posible elaborar una definición de este tipo de memorias sobre la dictadura a partir de rasgos claramente distintivos? La hipótesis principal de la cual partimos consistió en responder positivamente a esta pregunta: creíamos que se trataba de un conjuntos de memorias que pueden ser englobadas bajo una misma categoría, por poseer características que las delimitan claramente respecto a otros tipo de memorias - "oficiales", "dominantes", "hegemónicas", etc.-.

De esta pregunta-guía explicitada pudimos derivar muchas otras, las cuales, a su vez, nos sirvieron para orientarnos en nuestros objetivos específicos. En primer lugar, analizando las formas de relación existentes entre las memorias trotskistas y las memorias oficiales de la dictadura en el período 2014-2018. Aquí nos propusimos hacer hincapié, en primera instancia, sobre la manera en que es construida la memoria de la izquierda trotskista frente a la memoria kirchnerista de la dictadura, una memoria con características bien definidas; entre ellas: la legitimidad aportada por buena parte del movimiento de derechos humanos; la reivindicación selectiva y mistificadora de la militancia setentista; la responsabilización de actores no militares, etc. Podemos decir que se trata de una narrativa que logró volverse hegemónica, principalmente gracias a su respaldo estatal (Lvovich y Bisquert, 2008, pp. 81-84). Intentamos ver, entonces, si estábamos frente a una relación de total oposición, o si, por el contrario, en su clara disputa de sentidos, había ciertos tópicos discursivos compartidos o solapados. Y en segundo lugar, hicimos un análisis similar, en cuanto a lo 
formal, con respecto a la estructuración de la memoria trotskista frente a la memoria oficial del macrismo, intentando detectar los cambios y continuidades que aparecían en este nuevo período político abierto.

Otro de los puntos que nos interesó abordar fueron las formas de relación existentes con otros tipos de memorias - no oficiales, ni dominantes o hegemónicas-, memorias que poseen otras características particulares. Como sostiene Ludmila Da Silva Catela, existen "otros sistemas de clasificaciones”, que muchas veces no se corresponden "con las maneras de construcción de las memorias sobre la represión tantas veces escuchadas" (2010, p. 111). Estudiando las memorias de espacios locales distantes geográficamente de Buenos Aires, la autora encuentra lo que denomina como "memorias largas" o "memorias subterráneas", formas de recordar las violencias sufridas bajo categorías y periodos temporales distintos a los que impone la memoria estatal o de los centros de poder. Desde ese punto de vista, nos pareció pertinente indagar posibles conexiones y diferencias entre estas memorias particulares y nuestro objeto de estudio. El mismo ejercicio lo llevamos adelante con respecto a las memorias categorizadas por la misma autora como "denegadas" (p. 116), esto es, las memorias de militares y sus familiares; más específicamente, la configuración actual de las mismas, sintetizada en la consigna "Memoria Completa" (Salvi, 2009, pp. 104-110). Nos interesó aquí profundizar en dos aspectos de esta relación: primero, si había características compartidas entre las mismas; y segundo, ver hasta qué punto las memorias trotskistas se encargaban de confrontar con este tipo de memorias.

Por último, basándonos estrictamente en lo que nos permitían ver las fuentes trabajadas, abordamos los matices o diferencias existentes al interior de la izquierda trotskista con respecto a esta construcción memorial, para definir, finalmente, si era posible hablar de una sola memoria trotskista sobre la dictadura en términos generales.

Antes de pasar al desarrollo de esta investigación, quisiéramos señalar que, si bien existen varios trabajos historiográficos sobre las prácticas y los discursos de la izquierda argentina en la historia reciente, debemos decir, en primer lugar, que a partir del ciclo político abierto en 2003 con el kirchnerismo, estos estudios se focalizaron principalmente en las organizaciones armadas marxistas y peronistas de los años 1970 (Osuna, 2015). Por el contrario, el derrotero del resto de los partidos políticos de izquierda sigue siendo muy poco explorado. Podemos encontrar aquí ${ }^{1}$ algunos pocos trabajos que analizan los discursos y prácticas de grupos como el Partido Comunista (PCA), el Partido Comunista Revolucionario (PCR) y el Partido Socialista de los Trabajadores (PST). Con respecto a nuestro objeto de investigación, nos interesaron particularmente los estudios focalizados en el derrotero del PST -fusionado en el Movimiento al Socialismo (MAS) a fines de 1982-, principalmente por tratarse de la organización "madre" de la cual emergieron la mayoría de los partidos trotskistas actualmente existentes. Nos resultaron de mayor pertinencia, en este sentido, los trabajos de Florencia Osuna (2015) y Federico Sager (2013 y 2014), los cuales historizan las prácticas, pero fundamentalmente los discursos y representaciones de esta organización durante la dictadura y los primeros años de la democracia.

Sin embargo, más allá de estos aportes, debemos remarcar que no encontramos trabajos relacionados o referidos en términos específicos a nuestro objeto de investigación propiamente dicho; es decir, a la (re)construcción actual de las memorias de izquierda en general, y de la izquierda trotskista en particular. Es por ello que creemos que esta incipiente indagación puede ser un punto de partida novedoso en cuanto a la posibilidad de comenzar a historizar este tipo particular de memorias.

\section{LAS MEMORIAS TROTSKISTAS VS. LA MEMORIA KIRCHNERISTA.}

Podemos decir que lo que caracteriza a las memorias dominantes y/o hegemónicas en nuestro país, utilizando la definición de Da Silva Catela, es su unión "en torno al rechazo y la denuncia del terrorismo de Estado, básicamente representadas por los organismos de derechos humanos, que en la actual coyuntura política se juntan con el Estado para reivindicarlas" (2010, p. 104). Con "actual coyuntura política" la 
autora refiere al período abierto durante el kirchnerismo. Como ya adelantamos, este período no sólo va a implicar la estatización de estas memorias, sino el desarrollo de una nueva síntesis que va a lograr imponer su hegemonía. Esta síntesis, a partir de varios resortes estatales y a través de múltiples vías (gestos simbólicos, discursos, homenajes, creación de "lugares de memoria" y de archivos, políticas educativas, etc.), va a lograr establecer un nuevo enfoque respecto del pasado, con características bien definidas; entre ellas: la asociación de la violación de los derechos humanos con la imposición del modelo económico neoliberal; la romantización y mistificación selectiva de la militancia setentista (principalmente, focalizadas en la Juventud Peronista); la recuperación de una narrativa humanitaria (como en el caso de la CONADEP), que excluye (¿silencia?) a la violencia guerrillera como elemento sustancial del proceso histórico; etc. Además, cabe destacar que, si bien Néstor Kirchner hizo referencia en sus discursos a "otros sectores" en tanto responsables de la dinámica dictatorial -como la iglesia, la prensa y la clase política- (Lvovich y Bisquert, 2008, p. 87), uno de los rasgos más sobresalientes de la memoria kirchnerista consiste justamente en su no historización de esa violencia, omitiendo "las responsabilidades del Estado, las fuerzas armadas, la sociedad política y civil en las desapariciones previas al golpe” (Crenzel, 2016, p. 64).

Frente a esta memoria hegemónica, podemos decir que las representaciones trotskistas respecto de este pasado se posicionaron de manera sustancialmente antagónica, desde un lugar de oposición. En primer lugar, denunciando abiertamente al kirchnerismo como "cómplice" de los "genocidas" y perpetrador de la "impunidad" (Prensa Obrera, 27-3-14; Prensa on line de IS, 2-4-15 y 3-2-16). Y resaltando constantemente lo que para este movimiento constituye la "hipocresía del gobierno K en materia de derechos humanos" ( $L a$ Izquierda Diario, 25-3-15), consistente en la manipulación política y electoral, que "oculta" ciertas dimensiones del pasado en disputa (Prensa on line de IS, 2-4-15; Prensa on line del NMAS, 24-3-15). Esta denuncia se hace claramente extensiva hacia los organismos de derechos humanos que "fueron cooptados por el kirchnerismo y dejaron de seguir enfrentando sus políticas de impunidad" (Prensa on line de IS, 3-2-16). Sin embargo, ya en esta primera manifestación del antagonismo, podemos señalar un primer punto en común: la confluencia en los tópicos discursivos elaborados durante décadas por los organismos de derechos humanos. Aquí podemos ver que, si bien se apunta contra los organismos "cooptados", todas las fuentes consultadas no sólo recaen en tópicos tales como "dictadura cívico-militar", "terrorismo de Estado", "defensa de los Derechos Humanos", etc., sino que además exaltan constantemente la participación de las corrientes trotskistas en el Encuentro Memoria Verdad y Justicia (EMVyJ).

Esta confluencia en ciertos tópicos discursivos, sin embargo, no deja de estar nutrida de fuertes antagonismos, de una clara disputa por la apropiación de símbolos. En todos los artículos encontramos una resemantización del discurso hegemónico de los Derechos Humanos. Y esto se evidencia, principalmente, en tanto se remarcan de manera constante los atropellos actuales de un gobierno que se muestra como embanderado de las luchas de los organismos más representativos. La consigna omnipresente es: "contra la impunidad de ayer y de hoy". De esta forma, en primer lugar, se intenta asociar de manera directa al gobierno kirchnerista con la dictadura, exhibiéndolo como "cómplice" de los "genocidas" en la medida en que los juicios actuales contra los represores sólo se llevan a cabo "a cuentagotas" (Prensa on line de IS, 3-2-16), dejando a "miles de policías, militares, agentes de inteligencia y jueces que actuaron durante la dictadura y hoy siguen en funciones" sin castigo (Prensa on line de IS, 2-4-15), al igual que "la mayoría de los empresarios, curas" y "colaboradores políticos y sindicales" (La Izquierda Diario, 25-3-15). Pero no sólo eso: también se lo asocia resaltando el papel de complicidad de Cristina Fernández y Néstor Kirchner con respecto a los indultos del menemismo (Prensa on line de IS, 2-4-15), la desaparición de Julio López y la designación "del genocida Milani al frente del Ejército" (Alternativa Socialista, 11-3-15).

En segundo lugar, esta asociación (y la consecuente resemantización de los símbolos en disputa) se intenta establecer mediante otro tipo de operación discursiva que equipara, de cierta forma, el carácter sistemático de violación de los derechos humanos durante la dictadura con los casos actuales de "gatillo fácil”, el "etnocidio de los Qom", la "criminalización" y la "represión de las protestas sociales", el "Proyecto X de espionaje de 
Gendarmería", las "nuevas leyes antiterroristas", etc. Esta operación, desde nuestro punto de vista, va a ser la clave central para comprender la dinámica de estos tipos de memorias. ¿Por qué sostenemos esto? Porque este ejercicio discursivo de homologación entre los crímenes de la dictadura y los atropellos actuales de los aparatos represivos del Estado, no solo constituye la operación más repetida, sino que se articula de manera medular y sistemática con las demás características de las representaciones trotskistas respecto del pasado dictatorial. Veamos.

En todos los artículos analizados se manifiesta una representación bastante homogénea respecto de las "causas" del golpe de Estado de 1976. Lo que hubo detrás del régimen terrorista fue la necesidad de llevar adelante un "ajuste capitalista en beneficio de los grupos económicos, multinacionales y el imperialismo" (Prensa on line de IS, 3-2-16). Desde esta óptica,

el plan económico que instauraron Videla y Martínez de Hoz sigue vigente -más allá de los retoques cosméticos de los gobiernos electos posteriores-, esencialmente por cumplir con los pagos de una deuda externa contraída en esa época, la cual se sigue pagando puntualmente con ajuste y salarios y jubilaciones de pobreza, siendo el actual gobierno el que más deuda pagó (Prensa on line de IS, 2-4-15).

Si bien podemos decir que aquí encontramos otro punto de confluencia discursiva con la memoria hegemónica del kirchnerismo, en tanto se pone el foco sobre la relación entre el golpe militar y la imposición de un nuevo modelo económico, nuevamente esa confluencia se da en términos de una clara disputa, denunciando y ubicando al kirchnerismo en una (maquillada) línea de continuidad con los intereses económicos presentes detrás de la dictadura. Es en este sentido puntual en que el discurso trotskista denuncia al kirchnerismo como "cómplice del espionaje, de la impunidad y de mantener el aparato represivo del Estado intacto, garantizando que los empresarios ideólogos del genocidio sigan siendo los que tienen el poder en nuestro país" (La Izquierda Diario, 25-3-15. La bastardilla es propia). De esta manera se puede entender por qué estas memorias homologan los crímenes de la última dictadura con todo tipo de represión ejercida por el aparato estatal: dicho aparato y los intereses que representa seguirían siendo los mismos.

Pero aún queda otra característica más a destacar dentro de la estructuración de las memorias trotskistas frente a la hegemonía discursiva kirchnerista respecto del pasado dictatorial. Y nuevamente gira en torno a un punto de confluencia (también preñado de fuertes disputas simbólicas). Se trata de un tipo de rememoración que reivindica, al igual que la memoria oficial, la militancia de los años setenta. Sin embargo, la diferenciación aquí puede detectarse en dos planos. En primer lugar, si bien en los artículos encontramos una memoria mistificadora y romántica, podemos señalar la continuación de una tradición martirológica (Osuna, 2015, p. 96-99) que reivindica a los "luchadores" y los "caídos" (La Izquierda Diario, 25-3-15), figuras bélicas o combativas no utilizadas por la memoria hegemónica, que justamente intenta silenciar las violencias militantes. Además, podemos decir que los aspectos mistificadores y románticos de estos discursos también difieren, principalmente en la presentación idealizada de un bloque militante setentista homogéneo, que compartía un objetivo estratégico común: la revolución socialista en Argentina. Por ejemplo, el Nuevo MAS sostiene que mientras ellos no abandonan "el camino que nos legaron los 30.000 compañeros detenidos y desaparecidos", el kirchnerismo los rememora "pero oculta las banderas que ellos levantaron" (Prensa on line del NMAS, 24-3-15). A su vez, así como equiparan los horrores de la dictadura con la violencia estatal en todas sus formas tras la recuperación de la democracia, como contrapartida también homologan la lucha de los "30 mil" con las luchas del 2001, de "Maxi Kosteki, Darío Santillán", "Carlos Fuentealba", "Mariano Ferreyra”, etc. (Prensa on line del NMAS, 24-3-15; Prensa Obrera, 8-3-18).

Igualmente, en este punto, cabe destacar uno de los pocos matices que fuimos encontrando en la estructura y dinámica de las memorias trotskistas. Y es el caso de Izquierda Socialista que, si bien en su prensa destaca esa imagen homogénea de los "luchadores" del pasado (silenciando o callando, al igual que en los demás casos, sobre las diferencias abismales existentes en el campo de la izquierda en los años setenta), a su vez remarca la violencia pre-dictatorial sufrida por su partido antecesor (el PST) a manos de organizaciones como la Triple A (Prensa on line de IS, 3-2-16). Podemos decir, por lo tanto, que aunque sea de forma puntual -y como 
un aspecto más de diferenciación-, dentro de las memorias trotskistas aparecen nuevas temporalizaciones del terror. Si a ello le sumamos la referencia reiterada a "los desaparecidos en democracia" (Prensa on line del NMAS, 24-3-15), creemos que hay ciertos rasgos en común con las así definidas por Da Silva Catela como “memorias subterráneas". Hablaremos de ello más adelante.

\section{LAS MEMORIAS TROTSKISTAS VS. LA ¿MEMORIA MACRISTA?}

A diferencia de la memoria del gobierno kirchnerista, que posee características bien definidas y distinguibles, no es posible afirmar algo semejante respecto de la memoria oficial del macrismo, más allá de que, poco a poco, ya se vayan perfilando algunos rasgos sobresalientes. Como bien señala Crenzel, tras el ascenso de Mauricio Macri a la presidencia,

se ha verificado un marcado retroceso de las políticas de memoria, verdad y justicia (...) Se desmantelaron parcial o totalmente áreas que investigaban las responsabilidades corporativas con los crímenes dictatoriales, que aportaban pruebas a los juicios y/o asistían a las víctimas. (...) En paralelo, la genérica condena de la violencia y las referencias de igual tono a las víctimas marcan un giro discursivo que deja de lado el carácter distintivo de los crímenes de la última dictadura. Se comienza a asistir, entonces, a un nuevo ciclo en este largo proceso de luchas en el cual la voz del Estado vuelve a confrontarse con las ideas y políticas del movimiento de derecho humanos (Crenzel, 2016: 67).

Frente a esta nueva memoria emergente, las memorias trotskistas efectúan varias operaciones discursivas diferenciables. En primer lugar, caracterizan a esta memoria oficial a partir de formas de rememoración preexistentes: el negacionismo (Prensa on line de IS, 3-2-16; Alternativa Socialista, 11-3-15; La Izquierda Diario, 21-3-18; Prensa Obrera, 8-3-18), la "teoría de los dos demonios" e incluso la memoria menemista (Prensa Obrera, 8-3-18). Sin embargo, lo que prima es el señalamiento del constante ninguneo de la cifra de los “30 mil”. A partir de esta operación, las memorias trotskistas intentan remarcar la patente continuidad de la administración macrista con la impunidad de los “genocidas”. Pero, a la par, mientras señalan los supuestos rasgos distintivos de la memoria macrista, no dejan de resaltar que se trata de una memoria absolutamente conectada, también en términos de continuidad, con las políticas de impunidad inmediatamente anteriores, volviendo a poner el foco en los "atropellos" y gestos "cómplices" del kirchnerismo, como "la desaparición de Julio López”, "el Proyecto X” o la coronación de "Milani al frente del Ejército”.

Desde nuestro punto de vista, esta segunda operación debe ser entendida en base a las características específicas de la narrativa trotskista, ligada completamente a su explicita intencionalidad político-partidaria. Por más que se trate de un nuevo ciclo político, estas memorias no pueden dejar de referirse negativamente a sus adversarios y competidores (incluso, como veremos, replicando esta lógica competitiva al interior de su propia corriente).

Por otra parte, vemos que se replica nuevamente la operación consistente en homologar los crímenes de la dictadura con hechos represivos tales como la "criminalización de la protesta social", los casos de "gatillo fácil”, "los asesinatos de Santiago Maldonado y Rafael Nahuel", "la represión brutal a los Qom", etc. En este sentido, se remarcan sus propias luchas "en defensa de los derechos humanos de ayer y de hoy" (Alternativa Socialista, 11-3-15). De la misma forma, también se vuelven a equiparar las luchas pretéritas con las actuales, como también el accionar de los diversos actores, esta vez aprovechando uno de los hechos de mayor relevancia en el espacio público en el transcurso del año 2018 de administración macrista: los movimientos masivos a favor del aborto legal, seguro y gratuito:

La Iglesia Católica tuvo un rol importante en los años del genocidio, legitimando los crímenes de lesa humanidad e incluso participando con curas y capellanes. (...) Hoy es la misma institución, al mando de Bergoglio en el Vaticano, que se opone al derecho al aborto, legal seguro y gratuito (La Izquierda Diario, 21-3-18).

Este punto -el de la homologación tanto de represiones como de luchas- nos resulta sumamente atendible, en este nuevo contexto, ya que podemos llegar a advertir cierta confluencia en la operación discursiva 
(salvando las distancias estratégicas) con la memoria macrista. Como sostiene Crenzel (2016), el objetivo del macrismo, en su equiparación de violencias y víctimas, es diluir discursivamente el carácter distintivo de los crímenes de la última dictadura. Podemos sostener que, aún con distintos objetivos políticos, las memorias trotskistas incurren en el mismo tipo de intervención. Por un lado, es posible inferir (con cierto grado de certeza) que el gobierno nacional equipara violencias y víctimas pasadas con el intento de justificar sus políticas actuales (abiertamente neoliberales), confrontando en este punto con los discursos estrictamente políticos de la mayoría de los organismos de derechos humanos -es decir, en su faceta anti-neoliberal profundizada durante el kirchnerismo. Por su parte, las memorias trotskistas señalan la importancia de la violación actual de los derechos humanos, homologando violencias, víctimas y luchas, pero en este caso para denunciar la continuidad con los años del terror.

\section{AlgunAS COMPARACIONES POSIBLES}

Hasta aquí pudimos profundizar en la relación entre las memorias trotskistas y las memorias estatales durante los últimos cinco años. Pero creemos que, para poder llegar a establecer una caracterización más plena de estas memorias analizadas, nos faltaría encarar rigurosamente la relación de las mismas con otros tipos de memorias existentes, ya no ligadas al poder, sino periféricas, con intención de disputa pública o no. Por el carácter preliminar de este trabajo, ya dijimos que sólo las relacionaríamos con las -denominadas así por Ludmila Da Silva Catela- memorias “subterráneas" y “denegadas”. Pero aclaramos, desde ya, que este ejercicio solo puede servir como apertura de un camino a seguir, absolutamente necesario, si es que se desea detectar y señalar exhaustivamente todos los rasgos específicos de nuestro objeto de análisis.

Como ya señalamos, las memorias "subterráneas" o "largas" llevan ese título porque la autora encuentra en ellas formas de recordar las violencias sufridas bajo categorías y periodos temporales distintos a los que impone la memoria estatal o de los centros de poder. Se trata de memorias "menos 'políticamente correctas ', menos encuadradas" que, además, no logran efectuar "la transmisión en el espacio público de sus propios sentidos sobre el pasado" (2010, p. 117). La autora muestra que estas memorias, locales, del interior (más específicamente, de algunas comunidades de la provincia de Jujuy) no hacen uso de categorías tales como "centro clandestino de detención", "desaparecidos", "tortura" o "terrorismo de Estado". Tampoco tienen ninguna inhibición para hablar de sus militancias políticas revolucionarias. Pero quizás su diferenciación más fuerte -debido, según Da Silva Catela, a la lógica del entramado del poder político, represivo y económico del interior durante los años rememorados- parte de no tener en cuenta la temporalización construida por las diversas memorias estatales de post-dictadura: no consideran relevante el año 1976 ni el día 24 de marzo como marcos de referencia para hablar de una violencia distintiva (p. 114).

Es aquí donde encontramos un punto de confluencia con las memorias trotskistas: aun apareciendo en sólo dos fuentes, el uso de una temporalización diferente, que se extiende más atrás en el tiempo para hablar de las violencias estatales, no pareciera ser un rasgo distintivo de nuestro objeto de estudio. Sin embargo, rápidamente se pueden percibir las diferencias, que, desde nuestro punto de vista, sí le otorgan su especificidad. En primer lugar, las memorias trotskistas no sólo se remontan hacia atrás temporalmente, haciendo referencia a los atropellos del gobierno peronista antes de la dictadura (focalizándose en los crímenes Triple A), sino que -ahora sí, en todas las fuentes- se puede percibir que extienden esta indiferenciación hacia adelante, llegando a la actualidad. En segundo lugar, a diferencia de las memorias subterráneas, nuestras memorias establecen además una temporalización distintiva de carácter político, y que justamente por ello se transmite y se disputa en el espacio público. Y, por último, como ya vimos, las memorias trotskistas sí confluyen, claramente, con los tópicos discursivos generales de los organismos de derechos humanos y el Estado (aunque sea en términos de disputa por la apropiación de símbolos).

Con respecto a las memorias "denegadas", podemos decir, como adelantamos también en la introducción, que son representaciones que portan particularmente militares y sus familiares, que reivindican a los “ muertos 
por la subversión" y que en la actualidad se configuran sintéticamente bajo la consigna "Memoria Completa". Se trata de memorias que

pretenden ser reconocidas por el Estado nacional, solicitándolo formalmente y luchando en el espacio simbólico de la Plaza de Mayo bajo la consigna: 'la plaza es de todos'. Pero el Estado niega sus relatos y sentidos dados al pasado, y justifica esta negación afirmando la impureza de esas memorias, el origen nocivo de los relatos, principalmente porque provienen de comunidades identificadas o pertenecientes a la 'familia militar' (Da Silva Catela, 2010, pp. 119 y 120).

La autora las llama también "memorias perdedoras", no sólo porque no encuentran eco en el relato oficial, sino porque sus espacios de circulación y expresión primordialmente son las redes virtuales (las web, las cadenas de mails, etc.), operando en una suerte de accionar casi clandestino (p. 121). Por último, para Da Silva Catela estas memorias se "construyen en espejo" con la memoria hegemónica del kirchnerismo y los organismos de derechos humanos, aunque constituyendo una "relación de oposición". Con la metáfora de la construcción especular, la autora remarca que "las memorias denegadas copian en negativo las memorias dominantes. Fotos en blanco y negro, apelación a los lazos primordiales, uso de la figura femenina en los reclamos, consignas" (p. 120).

No podemos afirmar si existe hasta aquí, por parte de las memorias trotskistas, un intento de confrontar directamente con este tipo de memorias. Solo podemos establecer, como lo hicimos con las memorias "subterráneas", una comparación analítica. Vemos aquí ciertas similitudes y diferencias. En primer lugar, tanto las memorias denegadas como las trotskistas disputan simbólicamente el espacio público. Ambas memorias también (al menos con respecto a la memoria hegemónica del kirchnerismo) se paran desde un lugar de oposición al relato oficial, confluyendo en ciertos tópicos y formas de expresión (las memorias denegadas también reclaman "memoria, verdad y justicia"), pero estableciendo una clara disputa simbólica. Sin embargo, cabe señalar que las memorias trotskistas poseen una mayor visibilidad y legitimidad (participando de marchas masivas) y, aunque no sean reconocidas oficialmente, no son memorias denigradas ni rechazadas por su origen. Además, el carácter partidario también es distintivo de nuestras memorias, y, si bien comparte algunos rasgos formales, en el contenido resultan absolutamente antagónicas con respecto a estas memorias militares.

\section{A MODO DE CIERRE: ¿UNA MEMORIA TROTSKISTA?}

Hasta aquí pudimos indagar en torno a la estructura y la dinámica de las memorias trotskistas respecto de la última dictadura militar, profundizando en su relación con las memorias estatales y ejerciendo un incipiente estudio comparativo con memorias periféricas. Esto nos posibilitó detectar algunas características que parecieran ser sustanciales: 1- el abierto antagonismo con respecto a ambas memorias oficiales (y, por extensión, frente a las memorias de las organizaciones de derechos humanos más representativas); 2- la homologación tanto de represiones como de luchas; 3- la rememoración homogeneizante de la militancia setentista y su reivindicación en términos combativos; 4- una distintiva temporalización (política) de la represión; y 5- la confluencia en ciertos tópicos discursivos con la memoria kirchnerista (en un claro sentido de disputa simbólica).

Nos restaría, por último, intentar determinar si es posible hablar de una "memoria trotskista" en general para este período. Es decir: ¿Obtenemos un resultado satisfactorio englobando todas estas memorias analizadas bajo una sola categoría, o bien, por el contrario, hay que ejercer cierta cautela a partir de ciertos rasgos distintivos notorios? Creemos que aquí podemos aproximarnos a una afirmación más sustantiva, con mayor precisión, ya que se trata de una conclusión que parte únicamente de las fuentes con las que contamos. A lo sumo, habría que ampliar el número de artículos dedicados a la rememoración del 24 de marzo o ampliar la cantidad de partidos trotskistas analizados. Sin embargo, nos parece que a partir de las fuentes seleccionadas y por las características de los partidos elegidos (los más representativos), ya tenemos suficiente material para 
responder con firmeza. La respuesta es positiva. Si bien encontramos ciertos aspectos distintivos, como la reivindicación de IS respecto del papel del PST durante los años de la dictadura, o la denuncia del mismo partido respecto de la violencia precedente ejercida por organizaciones como la Triple A (algo que, casi con total seguridad, suscribiría cualquiera de las memorias de los demás partidos); creemos que se trata de diferencias no sustanciales. De hecho, en las fuentes se pueden ver ciertos choques al interior del mundo trotskista, como por ejemplo las denuncias del MAS (Prensa on line del NMAS, 18-3-18) o del PO (Prensa Obrera, 8-3-18) hacia el MST, con respecto al intento de este último partido de confluir en una sola marcha por el 24 de marzo junto al kirchnerismo (fundamentalmente para denunciar las políticas del macrismo). Sin embargo, creemos, nuevamente, que se trata de diferencias de forma y no de contenido; más de "rosca" política que de diferencias esenciales en cuanto a la forma de rememorar los hechos de nuestro pasado reciente. Por lo tanto, podemos afirmar, con un grado considerable de certeza a partir de los rasgos arriba sintetizados y enumerados, que es posible hablar de una memoria trotskista de la dictadura.

\section{REFERENCIAS}

CRENZEL, Emilio. (2016). "Entre la historia y la memoria. A 40 años del golpe de estado en la Argentina". Questoes \& Debates. Vol. 64. Número 2. pp. 39-69.

DA SILVA CATELA, Ludmila. (2010), "Pasados en conflicto. De memorias dominantes, subterráneas y denegadas". En: Bohoslavsky, E., et. al., Problemas de historia reciente del Cono Sur, Buenos Aires: Prometeo.

JELIN, Elizabeth. (2001), Los trabajos de la memoria, Madrid: Siglo XXI.

LVOVICH, Daniel; BISQUERT, Jaquelina. (2008). La cambiante memoria de la dictadura, Buenos Aires: Biblioteca Nacional.

OSUNA, Florencia. (2015). De la "revolución socialista" a la "revolución democrática": las prácticas politicas del Partido Socialista de los Trabajadores-Movimiento al Socialismo durante la última dictadura militar (1976-1983), La Plata: Universidad Nacional de La Plata; Los Polvorines: Universidad Nacional de General Sarmiento; Posadas: Universidad Nacional de Misiones.

SAGER, Federico. (2013) “'Herir a la democracia'. Construcción del otro negativo y uso de la polémica en discursos de Alfonsín y el MAS”. En: XVIJornadas Interescuelas/Departamentos de Historia. Departamento de historia de la Facultad de Filosofía y Letras. Universidad Nacional de Cuyo, Mendoza. Disponible en: http://cdsa.aacade mica.org/000-010/806

SAGER, Federico. (2014), "Momento fundacional y primeros pasos del MAS argentino (1982-1984)". En: II Jornadas de Ciencia Política del Litoral. Universidad Nacional del Litoral. Disponible en: http://www.fhuc.unl.edu.ar/materiales_congresos/cienciapolitica_2014/ pdf/4)\%20Democracia,\%20Partidos\%20y\%20Accion\%20Colectiva/Sager.pdf

SALVI, Valentina. (2009). “De vencedores a víctimas: 25 años de memoria castrense”. Temas y debates. $\mathrm{N}^{\circ} 17$. pp. 93-115.

\section{Fuentes}

Fuente 1: Prensa on line de Izquierda Socialista, 3/2/2014, "24 de marzo: Izquierda socialista junto al FIT en la marcha del Encuentro Memoria, Verdad y Justicia”, disponible en: http://www.izquierdasocialista.org.ar/index.php/noticias/nacionales/686-24-de-marzo-izquierda-socialist a-junto-al-fit-en-la-marcha-del-encuentro-memoria-verdad-y-justicia

Fuente 2: Prensa on line de Izquierda Socialista, 3/2/2016, “iPor un gran 24 de marzo!”, disponible en: http://www.i zquierdasocialista.org.ar/index.php/noticias/derechos-humanos/3017-por-un-gran-24-de-marzo-3 
Fuente 3: Prensa on line de IS, 2/4/2015, "Grandes marchas el 24 de marzo", disponible en: http://www.izquierdasocialista.org.ar/index.php/periodicos-ediciones-anteriores/el-socialista-n-288/1862 -grandes-marchas-el-24-de-marzo

Fuente 4: Diario Alternativa Socialista, 11/3/2015, “24 de marzo: no a la impunidad de ayer y de hoy", disponible en: http://as.mst.org.ar/2015/03/11/24-de-marzo-la-impunidad-de-ayer-de-hoy/

Fuente 5: Prensa on line del MST, 14/3/2018, "Debates de cara al 24 de marzo", disponible en : https://mst.org.ar/2 018/03/14/debates-de-cara-al-24-de-marzo-no-impunidad-ajuste-represion-de-macri-complices/

Fuente 6: Prensa on line del NMAS, 24/3/2015, “24 de marzo: la Plaza es de los que luchan”, disponible en: https:/ /www.mas.org.ar/? $\mathrm{p}=4912$

Fuente 7: Prensa on line del NMAS, 18/3/2018, "Un debate con el MST: Defendamos la independencia política del 24 de Marzo y del EMVyJ", disponible en: https://www.mas.org.ar/?p=15199

Fuente 8: Diario La Izquierda Diario, 25/3/2015, "24 de marzo: la marcha del Encuentro, Memoria, Verdad y Justicia y la izquierda", disponible en: https://www.laizquierdadiario.com/24-de-Marzo-la-marcha-del-Encuentro-Me moria-Verdad-y-Justicia-y-la-izquierda

Fuente 9: Diario La Izquierda Diario, 21/3/2018, "24 de marzo: ¿Por qué marchar en forma independiente del gobierno nacional y provincial?", disponible en: https://www.laizquierdadiario.com/24-de-marzo-Por-que-ma rchar-en-forma-independiente-del-gobierno-nacional-y-provincial

Fuente 10: Diario Prensa Obrera, 27/3/2014, "Un gran 24 de marzo", disponible en: https://prensaobrera.com/pol iticas/24307-un-gran-24-de-marzo

Fuente 11: Diario Prensa Obrera, 8/3/2018, "Qué 24 de marzo queremos", disponible en: https://prensaobrera.com /libertades-democraticas/41362-que-24-de-marzo-queremos

\section{Notas}

1 Sobre las percepciones del PC, el PCR y el PST sobre el golpe y la dictadura en el año 1976 ver: Campione, D. (2005), "La izquierda no armada en los años setenta. Tres casos, 1973-1976", en Lida, C.; Crespo, H., Yankelevich, P., (compiladores), Argentina, 1976. Estudios en torno al golpe de estado, México, Colegio de México, Centro de Estudios Históricos; Cernadas, J., y Tarcus, H. (2006/2007), "Las izquierdas argentinas y el golpe del 24 de marzo de 1976. Una sección documental”, en Revista Políticas de la Memoria, N 6/7, verano del 2006/2007; Vezetti, H., (2009), Sobre la violencia revolucionaria. Memoria y olvidos., Buenos Aires, Siglo Veintiuno Editores. Se recomienda ver también: Casola, N. (2012), Estrategia, militancia y represión. El Partido Comunista de Argentina bajo la última dictadura militar, 1976,1983, Tesis de doctorado en Historia, Facultad de Filosofia y Letras, Universidad de Buenos Aires; y Mangiantini, M. (2014), El trotskismo y el debate en torno a la lucha armada. Moreno, Santucho y la ruptura del PRT, Buenos Aires, Controversias.

\section{NotAS DE AUTOR}

\footnotetext{
El autor del artículo se encuentra finalizando sus estudios en el Profesorado Universitario de Educación Superior en Historia (UNGS). Fue becario en Docencia en la asignatura Historia Latinoamericana II durante el año 2018, y actualmente se encuentra desarrollando una beca de Investigación y Docencia en Problemas del Conocimiento Histórico. Es además estudiante del Profesorado Universitario de Educación Superior en Filosofía y de la Licenciatura en Economía Política en la misma casa de estudios. Es miembro del Programa de Historia Contemporánea (PHiC) perteneciente al Instituto de Desarrollo Humano (UNGS). Ha publicado reseñas y artículos sobre temáticas diversas (populismos, Revolución Rusa, historia reciente) en varias revistas, entre ellas: Tiempo Histórico, Claves, Contextos, etc.
} 